\title{
ATRIBUTOS DO SOLO E BIOMASSA RADICULAR APÓS QUATRO ANOS DE SEMEADURA DIRETA DE FORRAGEIRAS DE ESTAÇÃO FRIA EM CAMPO NATURAL DESSECADO COM HERBICIDAS ${ }^{(1)}$
}

\author{
E. PÉREZ GOMAR ${ }^{(2)}$, J . M. REICHERT ${ }^{(3)}$, \\ D. J . REINERT ${ }^{(3)} \&$ F. GARCÍA(4)
}

\begin{abstract}
RESUMO
Os campos naturais, desenvolvidos sobre solos arenosos da região norte do Uruguai, são compostos por espécies forrageiras, sobretudo de gramíneas de produção estacional, com baixa produtividade no inverno. 0 objetivo deste estudo foi avaliar o efeito da dessecação do campo natural no estabelecimento de espécies de estação fria em atri butos do solo e bi omassa radicular. 0 estudo, iniciado em 1994, utilizou delineamento experimental de blocos ao acaso com parcelas subsubdivididas, com três repetições. Nas parcelas principais, em 1994, foram aplicados os tratamentos com herbicidas (paraquat $0,60 \mathrm{~g} \mathrm{ha}^{-1} \mathbf{i}$.a., glifosate $0,36 \mathrm{~g} \mathrm{ha}^{-1} \mathrm{i}$.a. e glifosate $1,44 \mathrm{~g} \mathrm{ha}^{-1} \mathrm{i}$.a.) e testemunha sem herbicida em campo natural para a semeadura de pastagens de inverno. Nessas parcelas, a pastagem de inverno foi aveia preta (Avena strigosa L.), triticale (X TriticosecaleWittmack) e azevém (Lolium multiflorum L.). As subparcelas foram formadas pela reaplicação ou não dos herbicidas em 1995 e as subsubparcelas foram formadas pela reaplicação ou não dos herbicidas em 1996. As amostras de solo para determinar a biomassa radicular, a densidade do solo, o carbono (C) orgânico do solo, bases trocáveis, Al trocável e o pH do solo foram extraídas separadamente, em três subamostras, usando cilindro metálico de $7,65 \mathrm{~cm}$ de diâmetro e $40 \mathrm{~cm}$ de comprimento. Os monolitos extraídos foram estratificados até $30 \mathrm{~cm}$ de profundidade nas camadas de 0-5, 5-10, 10-15, 15-20 e 20-30 cm. A biomassa radicular foi maior na testemunha do que a média dos tratamentos com herbicidas somente na camada de 0-5 cm, e, entre os tratamentos com herbicidas, a biomassa radicular foi maior com paraquat do que com o glifosate.
\end{abstract}

\footnotetext{
(1) Parte da Tese de Mestrado do primeiro autor, apresentada ao Programa de Pós-Graduação em Agronomia, UFSM. Parcialmente financiada pelo Pronex-CNPq/FI NEP. Recebido para publicação em agosto de 2000 e aprovado em setembro de 2001.

(2) Engenheiro-Agrônomo, Pesquisador do Instituto Nacional de Investigación Agropecuaria del Uruguay - INIA. Ruta 5, Km 386. Tacuarembó, Uruguay. E-mail: eperez@tb.inia.org.uy

(3) Engenheiro-Agrônomo, Professor Titular do Departamento deSol os da Universidade Federal deSanta Maria - UFSM. CEP 97105900 Santa Maria (RS). Pesquisador do CNPq. E-mail: reichert@ccr.ufsm.br

(4) Engenheiro-Agrônomo, Profesor Titular da Facultad de Agronomía de la Universidad de la República, Garzón 780. Montevideo, Uruguay. E-mail: fgarciap@fagro.edu.uy
} 
A reaplicação de herbicidas, em 1995 e 1996, também ocasionou redução da biomassa radicular. Houve alta correlação positiva de $\mathrm{C}$ orgânico com a biomassa radicular. A redução de $\mathrm{C}$ orgânico para o tratamento mais agressivo de controle químico (glifosate 1,44 g i.a. ha-1) foi de 13\%. Não houve efeito dos tratamentos sobre as bases trocáveis, porém houve aumento no teor de Al trocável e na densidade do solo e redução na estabilidade de agregados com a redução do teor de matéria orgânica. O sistema com maior aplicação de herbicidas, desenvolvido para maior produção de forragem ínvernal, e com maior agressividade no controle do campo natural provocou maior transformação na comuni dade vegetal, resultando em menor biomassa radicular e C orgânico, com conseqüências negativas quanto à acidez do solo e estrutura do solo.

Termos de indexação: raízes, estrutura do solo, carbono orgânico, manejo de pastagens, alumínio trocável.

\section{SUMMARY: SOIL PROPERTIES AND ROOT SYSTEM AFTER FOUR YEARS OF DIRECT DRILLING OF WINTER GROWING FORAGE ON A NATIVE GRASSFIELD DISSECTED WITH HERBICIDES}

Natural grassfields devel oped on sandy soils from N orthern Uruguay are formed by communities of forage species, composed mainly of seasonal growing grasses, with low biomass production during thefall/ winter period. Theobjective of this study was to evaluate the effect of herbicides, applied on nativegrassfiel d to established winter forage species, on soil properties and root biomass. This experiment began in 1994 and was established as a completebl ock design, with threereplications. In themain plots, to establish winter-growing the forage-species black oat (Avena strigosa L.), triticale (X Triticosecale Wittmack), and ryegrass (Lolium multiflorum L.) on native grassfield, herbicides were applied (paraquat $0,60 \mathrm{~g} \mathrm{ha}^{-1}$ a.i., glyphosate $0,36 \mathrm{~g} \mathrm{ha}^{-1}$ a.i., glyphosate $1,44 \mathrm{~g}$ ha-1 a.i.) and a test without herbicide was used for comparison. Themain plots were divided in 1995 forming a splitplot design, where each plot received the same treatments on a half plot. The split-plots were divided in split-split-plot design in 1996, where each split-plot received the same treatments on a half split-plot. Soil samples to measure root biomass, bulk density, soil organi c carbon, exchangeablebases and al uminum, and soil pH weretaken in threeseparate samplings using a $7.65 \mathrm{~cm}$ diameter by $40 \mathrm{~cm}$ long metallic cylinder. The extracted soil monol iths werestratified down to $30 \mathrm{~cm}$ to thefol lowing depths: 0-5, 5-10, 10-15, 15-20 and $20-30 \mathrm{~cm}$. Root bi omass was higher whereno herbicidewas applied, as compared to herbicide treatments only at $0-5 \mathrm{~cm}$ depth as well as for paraquat application, as compared to glyphosate. The continuous herbicide application in 1995 and 1996 produced progressive root biomass reduction. There was a high positive correlation between root biomass and soil organic carbon (SOC) and the latter reduced $13 \%$ due to the higher rate of chemical control (1.44 $\mathrm{g} \mathrm{ha}^{-1}$ a.i. of glyphosate applied in 1994, 95 and 96). There was no effect of tested treatments on exchangeable bases, but $\mathrm{Al}^{3+}$ was affected. SOC changes were closely related to changes in soil structure, increasing bulk density and decreasing aggregatestability. Thesystem with high rate of herbici deuse, devel oped to obtain high winter forage bi omass production and suppression of native grasses, induced great changes on plant community presenting, as a consequence, less root biomass and SOC with negative effect on soil acidity and aggregation.

Index terms: roots, soil structure, soil organic carbon, pasture management, exchangeable aluminum.

\section{INTRODUÇÃO}

O campo natural desenvolvido sobre solos arenosos da região norte do Uruguai tem uma produção forrageira que se caracteriza por marcada estacionalidade, resultante da composição botânica. As pastagens naturais, com predominância de espécies estivais, apresentam bons níveis de produção de forragem na estação quente e severos déficits no período de estação fria. Por isso, espécies invernais anuais, como aveia e azevém, têm sido introduzidas com a finalidade de suprir o déficit forrageiro em sistemas convencionais de preparo do solo. Nesse tipo de preparo, as propriedades físicoquímicas dos solos arenosos são degradadas (Pérez Gomar \& Bemhaja, 1992). A utilização da semeadura 
direta de espécies forrageiras constitui excelente alternativa para o manejo desses solos, uma vez que provoca mínima mobilização de solo na linha de semeadura e reduz sua degradação.

Com a introdução de novas espécies às comunidades vegetais estabelecidas, provocam-se alterações ou distúrbios na comunidade (Carámbula et al., 1994), e o ecossistema reage a esses distúrbios, provocando uma substituição de espécies (Whalley, 1994). A aplicação anual de herbicidas sistêmicos modifica a composição vegetal das pastagens naturais e, quanto maior a dose utilizada, maior a redução de espécies que compõem a comunidade, com substituição de espécies perenes por anuais (Berretta et al., 1997).

Os diferentes sistemas de manejo de sol o alteram a concentração do carbono orgânico no solo. O conhecimento dessa mudança é importante para predizer os efeitos sobre o ecossistema e para estabelecer estratégias de manejo que permitam obter uma produção sustentável (Rasmussen \& Collins, 1991). O teor de carbono orgânico do sol o é um dos indi cadores da qualidade do solo consi derado dos mais importantes, por alterar a dinâmica de nutrientes, propriedades físicas e biológicas e características produtivas do solo (Swift \& Woomer, 1993). Além disso, está relacionado dir etamente com aspectos da poluição ambiental pela liberação do carbono à atmosfera, provocando aumento do efeito estufa e, conseqüentemente, mudança climática (Doran \& Parkin, 1994).

Variações nos teores de matéria orgânica modificam as condições físicas do solo, manifestandose pelas alterações nos atributos físicos, tais como: estrutura, densidade do solo, aeração, retenção de água, drenagem e consistência do solo. Carpenedo \& Mielniczuk (1990), Paladini \& Mielniczuk (1991) e Silva \& Mielniczuk (1997) assinalaram que os sistemas radiculares de gramíneas perenes apresentam boa eficiência na agregação dos solos.

As práticas de manejo influem nos teores de matéria orgânica e, portanto, na CTC (Bayer \& Mielniczuk, 1997), com incrementos significativos na CTC para pequenos incrementos de matéria orgânica. Em solos arenosos (Podzólico VermelhoAmarelo) do U ruguai, Duran (1985) observou que a correlação entre a CTC e o teor de C orgânico foi muito alta ( $r=0,896)$, enquanto a correl ação entre a CTC e oteor de argila foi menor $(r=0,66)$, em virtude do predomínio de argila caol inítica (Pazos, 1981) que tem baixa CTC.

Neste trabalho, testou-se a hipótese de que a utilização de herbicidas sistêmicos no sistema de semeadura direta de forrageiras anuais de estação fria muda a comunidade de espécies que compõem o campo natural, causando a redução da biomassa radicular, diminuindo o teor de $\mathrm{C}$ orgânico do solo, provocando modificações nas propriedades físicas e químicas do solo.

\section{MATERIAL E MÉTODOS}

\section{Descrição da área experimental e dos trata- mentos}

O experimento foi realizado no campo experimental "La Magnolia", do Instituto Nacional de I nvestigación Agropecuária (I NIA), no departamento de Tacuarembó, no U ruguai. Geograficamente, a área encontra-se na coordenada $31^{\circ} 42^{\prime} 30.3^{\prime \prime}$ latitude sul e $55^{\circ} 49^{\prime} 33.1^{\prime \prime}$ longitude oeste, numa altitude de $140 \mathrm{~m}$. Climaticamente, a região é definida como Cfa, mesotermal úmida, de acordo com a dassificação de Köppen (Duran, 1985), apresentando uma temperatura média menor do que ${ }^{\circ}{ }^{\circ} \mathrm{C}$ no mês mais frio, mas superior a -3ㄷ, etemperatura média mai or do que $22^{\circ} \mathrm{C}$ no mês mais quente, ausência de estação seca e com preci pitação mai or do que $30 \mathrm{~mm}$ no mês mais seco do verão. A preci pitação média anual éde $1.292 \mathrm{~mm}$, com desvio-padrão de $220 \mathrm{~mm}$.

O solo é classificado como Argissolo VermelhoAmarelo distrófico arênico com textura francoarenosa no horizonte $A$ e vegetação de pastagem natural, constituída, predominantemente, de espécies gramíneas estivais. O horizonte $A$, de $60-70 \mathrm{~cm}$ de espessura, tem $800 \mathrm{~g} \mathrm{~kg}^{-1}$ de areia (predominantemente fina e muito fina), $100 \mathrm{~g} \mathrm{~kg}^{-1}$ de silte e $100 \mathrm{~g} \mathrm{~kg}^{-1}$ de argila; o teor médio de C orgânico é de 8 a $11 \mathrm{~g} \mathrm{~kg}^{-1}$, e o teor de Al trocável é de $1,0 \mathrm{cmol}_{\mathrm{C}} \mathrm{kg}^{-1}$. O horizonte $\mathrm{B}$ tem $640 \mathrm{~g} \mathrm{~kg}^{-1} \mathrm{de}$ areia, $80 \mathrm{~g} \mathrm{~kg}^{-1}$ de silte e $280 \mathrm{~g} \mathrm{~kg}^{-1}$ de argila; o teor médio de $C$ orgânico é de $5 \mathrm{~g} \mathrm{~kg}^{-1}$, e o teor de Al trocável é de $2,0 \mathrm{cmol}_{\mathrm{c}} \mathrm{kg}^{-1}$.

O delineamento experimental utilizado foi de blocos ao acaso, arranjados em parcelas subsubdivididas, com três repetições. Nas parcelas principais, foram aplicados os tratamentos com herbicidas em campo natural para a instalação de pastagens de inverno: paraquat $0,60 \mathrm{~g} \mathrm{ha}^{-1}$ i.a., glifosate $0,36 \mathrm{~g} \mathrm{ha}^{-1}$ i.a., gl ifosate $1,44 \mathrm{~g} \mathrm{ha}^{-1}$ i.a., todos aplicados em 1994, e testemunha sem herbicida. As subparcelas foram formadas pela reaplicação ou não dos herbicidas em 1995, e as subsubparcel as foram formadas pela reapli cação ou não dos herbicidas em 1996. As parcelas principais mediram $10 \times 15 \mathrm{~m}$, as subparcelas $5 \times 15 \mathrm{~m}$ e as subsubparcelas $5 \times 7,5 \mathrm{~m}$.

Antes do início do experimento, a área era pastejada por bovinos e ovinos. Nos anos de $1994 \mathrm{e}$ 1995, uma mistura de $130 \mathrm{~kg} \mathrm{ha}^{-1}$ de aveia preta e $20 \mathrm{~kg} \mathrm{ha}^{-1}$ de azevém foi semeada em semeadura direta e, nos anos de 1996 e 1997, uma mistura de $140 \mathrm{~kg} \mathrm{ha}^{-1}$ de triticale e $20 \mathrm{~kg} \mathrm{ha}^{-1}$ de azevém. A adubação, em todos os anos, consistiu de $40 \mathrm{~kg} \mathrm{ha}^{-1}$ de nitrogênio e $80 \mathrm{~kg} \mathrm{ha}^{-1}$ de fósforo, aplicados na semeadura, e $60 \mathrm{~kg} \mathrm{ha}^{-1}$ de nitrogênio, aplicados no perfilhamento. No ano de 1997, a aplicação dos tratamentos com herbicidas ocorreu em 28/04 e a semeadura foi realizada em 07/05. 
A área experimental foi manejada com exclusão de animais e sem capina mecânica, durante todo o período experimental. Antes da aplicação dos herbicidas, foi feita uma roçada com a finalidade de uniformizar a altura da cobertura vegetal.

\section{Amostragens e análises de solo e raízes}

Amostras de solo foram extraídas usando um cilindro metálico de 7,65 cm de diâmetro e $40 \mathrm{~cm}$ de comprimento, em julho de 1997, 60 dias após a semeadura de triticale/azevém. Houve três amostragens distintas e específicas para determinações de (a) biomassa radicular, (b) densidade do sol o e (c) C orgânico, bases trocáveis, Al trocável e pH do solo. Os monolitos extraídos foram estratificados até $30 \mathrm{~cm}$ de profundidade nas camadas de 0-5, 5$10,10-15,15-20$ e $20-30 \mathrm{~cm}$.

O monolito extraído para avaliar a biomassa radicular foi coletado na entrelinha da cultura de inverno. O método consistiu em lavagem das raízes de cada camada de solo, secagem com papel e posterior pesagem (Cook \& Stubbendieck, 1986). A biomassa radicular foi expressa como massa fresca de raízes por unidade de volume de solo.

O C orgânico foi determinado por digestão úmi da com calor e dicromato de potássio (Tinsley, 1967). O estoque de $\mathrm{C}$ foi calculado por camada de solo até à profundidade de $30 \mathrm{~cm}$, conforme a densidade do solo. Os cátions trocáveis básicos ( $\mathrm{Ca}, \mathrm{Mg}, \mathrm{Na}$ e K) foram extraídos com acetato de amônio $1 \mathrm{~mol} \mathrm{~L}^{-1}$ a pH 7, com posterior determinação do teor de cálcio e magnésio, por espectrofotometria de absorção atômica, ede potássio e sódio, por espectrofotometria de emissão (Thomas, 1982). O alumínio e o hidrogênio trocáveis (acidez trocável) foram extraídos com KCl 1 mol L-1, com posterior titulação com NaOH (Thomas, 1982). Como a acidez trocável $(\mathrm{H}+\mathrm{Al})$ é composta, em geral, por alta percentagem de Al trocável para os solos considerados (Bohn et al., 1993), usar-se-á somente o termo Al trocável. O $\mathrm{pH}$ foi medido em água e em $\mathrm{KCl} 1 \mathrm{M}$.

A densidade do solo foi determinada mediante secagem a $105^{\circ} \mathrm{C}$ e posterior pesagem das amostras de volume conhecido. A estabilidade de agregados foi avaliada nas profundidades de 0-5 e 5-10 cm em amostras coletadas, em março de 1998, nos tratamentos glifosate $1,44 \mathrm{~g} \mathrm{ha}^{-1}$ i.a. e paraquat $0,60 \mathrm{~g} \mathrm{ha}^{-1}$ i.a. aplicados todos os anos e na testemunha. O método utilizado foi o de Kemper \& Chepil (1965), que consiste no tamisamento dos agregados em água, utilizando peneira de diâmetro de abertura de malha de 4,76; 2,00; 1,00 e 0,21 mm. Os resultados foram expressos em diâmetro médio ponderado (DMP) egeométrico (DMG) deagregados estáveis em água e distribuição de tamanho dos agregados.

\section{Análise estatística}

O teor e estoque de C orgânico, densidade de raízes, densidade do solo, soma de bases, $\mathrm{Ca}, \mathrm{Mg}, \mathrm{K}$ e $\mathrm{Na}, \mathrm{Al}$ trocável, $\mathrm{pH}$ em água e em $\mathrm{KCl}$ foram analisados, usando o pacote estatístico SAS, pela análise de variância em cada camada, tendo sido as somas de quadrados dos componentes de efeitos principais, desubtratamentos, desubsubtratamentos e das interações divididas em contrastes ortogonais de um grau de liberdade. Os contrastes e seus significados foram os seguintes:

Entre os tratamentos de 1994 (parcelas principais)

1) T vs. O (testemunha versus outros): compara a média do tratamento sem herbicida com a média das médias dos tratamentos que receberam herbicidas (paraquat 0,6 $\mathrm{g} \mathrm{ha}^{-1} \mathrm{i}$.a.; glifosate $0,36 \mathrm{~g} \mathrm{ha}^{-1}$ i.a.; glifosate 1,44 $\mathrm{g} \mathrm{ha}^{-1}$ i.a.).

2) $P$ vs. $G$ (paraquat $0,6 \mathrm{~g} \mathrm{ha}^{-1}$ i.a. versus glifosate $0,36 \mathrm{~g} \mathrm{ha}^{-1}$ i .a. eglifosate $1,44 \mathrm{~g}$ ha-1 i.a.): compara a média do tratamento que recebeu paraquat $0,6 \mathrm{~g} \mathrm{ha}^{-1}$ i.a. com a média dos tratamentos que receberam glifosate (glifosate $0,36 \mathrm{~g} \mathrm{ha}^{-1} \mathrm{i}$.a. e glifosate 1,44 $\mathrm{g} \mathrm{ha}^{-1}$ i.a.).

3) G1 vs. G4 (gl ifosate $0,36 \mathrm{~g} \mathrm{ha}^{-1}$ i.a. versus glifosate 1,44 $\mathrm{g} \mathrm{ha}^{-1}$ i.a.): compara a média do tratamento que recebeu $0,36 \mathrm{~g} \mathrm{ha}^{-1}$ i.a. de gl ifosate com o que recebeu $1,44 \mathrm{~g} \mathrm{ha}^{-1} \mathrm{i}$.a. de glifosate.

Entre os tratamentos de 1995 (parcelas subdivididas)

4) 95 sim vs. não: compara a média das médias dos subtratamentos que, em 1995, receberam novamente o tratamento de 1994 com a média dos tratamentos que não o receberam.

Entre os tratamentos de 1996 (parcelas subsubdivididas)

5) 96 sim vs. não: compara os subsubtratamentos que, em 1996, receberam o tratamento de 1994 com os que não o receberam.

Interações 94 × 95

6) $T$ vs. 0,95 sim vs. não: testa se houve uma mudança significativa na diferença explicada para o contraste 1 (1994), quando os tratamentos foram ou não repetidos em 1995.

7) $P$ vs. G, 95 sim vs. não: testa se o contraste 2 mudou ao serem repetidos ou não os tratamentos em 1995.

8) G1 vs. G4, 95 sim vs. não: testa se o contraste 3 mudou ao serem repetidos ou não os tratamentos em 1995.

Interações 94 × 96

9) T vs. O, 96 sim vs. não: testa se o contraste 1 mudou ao serem repetidos ou não os tratamentos de 1994 em 1996. 
10) P vs. G, 96 sim vs. não: testa se o contraste 2 mudou ao serem repetidos ou não os tratamentos de 1994 em 1996.

11) G1 vs. G4, 96 sim vs. não: testa se o contraste 3 mudou ao serem repetidos ou não os tratamentos de 1994 em 1996.

\section{Interações 95 x 96}

12) 95 sim vs. não, 96 sim vs. não: testa se as diferenças em aplicar ou não aplicar em 1995 foram alteradas por aplicação ou não em 1996.

Interações 94 × 95 × 96

13) T vs. 0,95 sim vs. não, 96 sim vs. não: testa se o contraste 6 mudou por terem sido aplicados novamente ou não os tratamentos de 94 em 96.

14) P vs. G, 95 sim vs. não, 96 sim vs. não: testa se o contraste 7 mudou por terem sido aplicados novamente ou não os tratamentos de 94 em 96.

15) G1 vs. G4, 95 sim vs. não, 96 sim vs. não: testa se o contraste 8 mudou por terem sido aplicados novamente ou não os tratamentos de 94 em 96.

Os resultados discutidos neste trabalho foram significativos a 5\% de probabilidade de erro tipo I.

Para o diâmetro médio ponderado (DMP) e geométrico (DMG) e distribuição de tamanho de agregados, foram considerados somente os três tratamentos citados anteriormente. Por esse motivo, o arranjo experimental simplificou-se a blocos ao acaso com três tratamentos e três repetições, realizando-se a análise de variância e as médias comparadas pel o teste DMS a 5\% de probabilidade.

Equações deregressãolinear múltipla ("stepwise") foram calculadas entre biomassa radicular, Al trocável e densidade do sol o com atributos químicos e físicos do solo. I gualmente, foram ajustadas regressões lineares entre $C$ orgânico eprofundidade, entre C orgânico e biomassa radicular e entre C orgânico e Al trocável.

\section{RESULTADOS E DISCUSSÃO}

\section{Biomassa radicular}

A biomassa radicular na camada de $0-5 \mathrm{~cm}$ do solorepresentou $70 \%$ do total de raízes. Na camada de 5-10 cm, essa biomassa foi reduzida drasticamente, totalizando $12 \%$ da massa total (Figura 1 ). Resultados semel hantes foram encontrados por Soriano (1991) em solo do pampa argentino, onde a distribuição da biomassa radicular de campos naturais teve uma concentração de mais de $65 \%$ nos primeiros $10 \mathrm{~cm}$ do solo e, aproximadamente, $85 \%$ até $30 \mathrm{~cm}$ de profundidade. Merten \& Mielniczuk

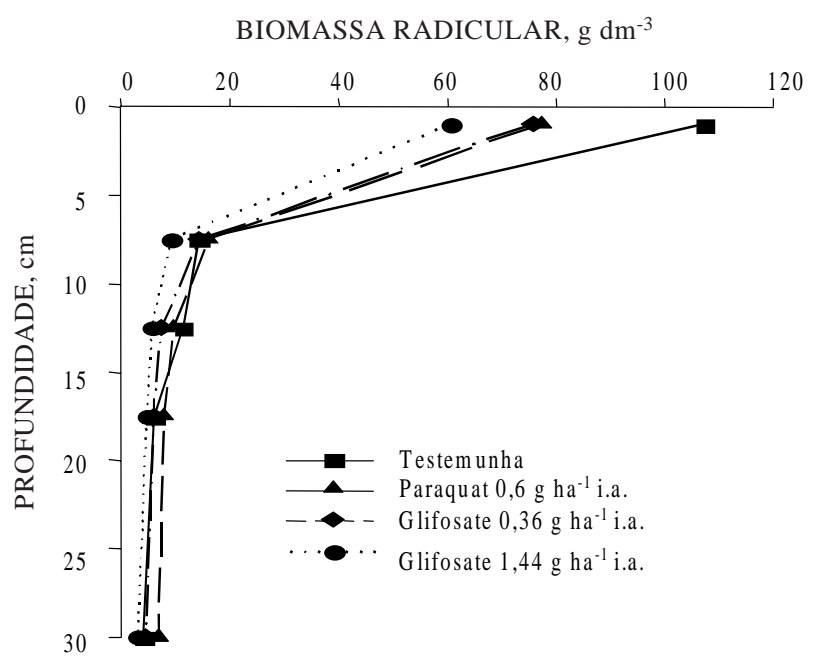

Figura 1. Variação da biomassa radicular com a profundidade do solo para diferentes tratamentos com herbicidas.

(1991) encontraram que mais de $70 \%$ da biomassa radicular concentrava-senos primeiros $10 \mathrm{~cm}$ do solo, para as culturas de aveia preta, trigo e soja, tanto no preparo convencional como na semeadura direta.

Os tratamentos de controle da vegetação mostraram diferenças somente nos primeiros $5 \mathrm{~cm}$ de solo (Figura 1). A biomassa radicular nos primeiros $5 \mathrm{~cm}$ do solo da testemunha foi maior do que a média dos tratamentos que tiveram aplicação de herbicida (contraste 1 ). A biomassa radicular na testemunha foi de $107 \mathrm{~g} \mathrm{dm}^{-3}$, enquanto a média dos tratamentos com herbicida foi de $70 \mathrm{~g} \mathrm{dm}^{-3}$. Isso está relacionado com as alterações provocadas pelos herbicidas sobre a composição botânica do campo natural, queafeta diretamentea biomassa radicular, que predominantemente se localiza nos primeiros $5 \mathrm{~cm}$ de profundidade do solo (Figura 1).

As raízes das espécies do campo natural apresentaram col oração mais escura easpecto mais envel hecido. As raízes que se encontravam no tratamento de glifosate $1,44 \mathrm{~g} \mathrm{ha}^{-1} \mathrm{i}$.a. apresentaram coloração mais clara e aspecto mais tênue, evidenciando que, do mesmo modo que houve substituição de espécies, identificável pela parte aérea, também ocorreu alteração quantitativa e qualitativa no sistema radicular.

A biomassa radicular foi maior nos tratamentos com paraquat do que com gl ifosate (contraste 2 ) nas camadas de $15-20$ e $20-30 \mathrm{~cm}$ (Figura 2a). Essa maior biomassa radicular no tratamento com herbicida de contato (paraquat), em relação ao herbicida sistêmico (glifosate), deveu-se à menor alteração da proporção de espécies perenes na composição botânica, permanecendo maior número de raízes permanentes. 
A diferença entre as duas doses de glifosate não foi significativa (contraste 3 ). A reaplicação de herbicida em 1995 versus a não-reaplicação mostrou tendência à maior biomassa radicular quando não se reaplicou herbicida em relação à reaplicação. Essa diferença somente foi significativa na profundidade

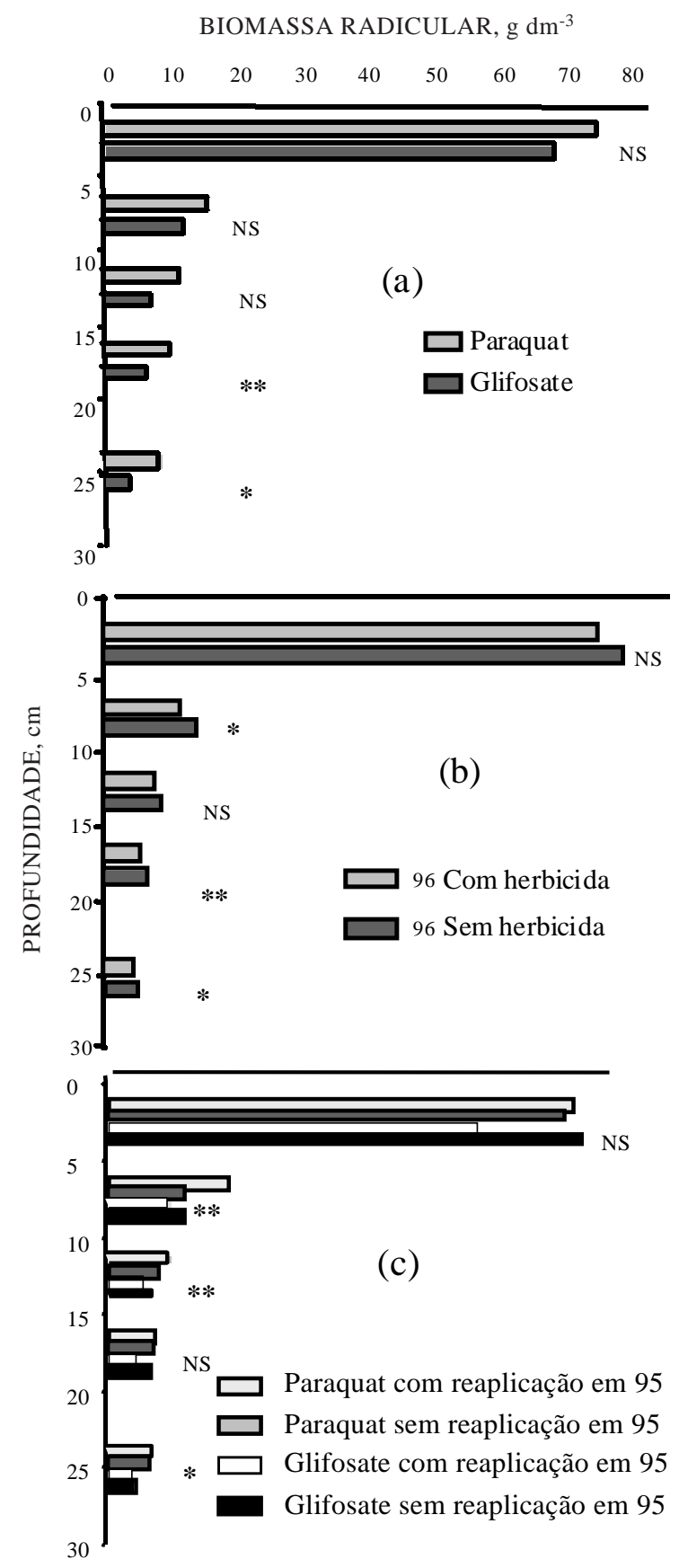

Figura 2. Variação da biomassa radicular com a profundidade do solo para tratamentos com os herbicidas paraquat e glifosate (a), com reaplicação ou não de herbicidas em 1996 (b) e com reaplicação ou não de herbicidas paraquat e glifosate em 1995 (c). de $15-20 \mathrm{~cm}$, encontrando-se mais biomassa sem aplicação de herbicida em 1995. Esse efeito foi semel hante ao observado quando se aplicou herbicida de contato em contraste à aplicação de sistêmico que teve menor efeito de substituição de espécies e seus respectivos sistemas radiculares.

Em 1996, a reaplicação de herbicida reduziu a biomassa radicular em todas as profundidades (Figura 2b). Essas diferenças foram significativas (contraste 5), nas profundidades de 5-10, 15-20 e 20-30 cm, provavelmente por causa dos efeitos imediatos que provocaram os herbicidas sobre a vegetação existente, repercutindo na biomassa radicular. Quandonão se aplicou herbicida em 1996, percebeu-se uma reconstituição da vegetação e, conseqüentemente, da bi omassa radicular, especialmentenas parcelas que receberam herbicida de contato e baixa dose de glifosate.

Analisando os contrastes de interações, verificouse que o contraste 7 foi significativo (Figura 2c). Para o paraquat, houve a mesma ou maior biomassa radicular quando se aplicou herbicida em 1995, comparado com a não-reaplicação; no entanto, para o glifosate, houve redução na biomassa radicular quando o herbicida foi aplicado nesse ano. As diferenças significativas ocorreram nas profundidades de 5-10, 10-15 e 20-30 cm, mostrando a ação menos agressiva na redução de espécies permanentes do paraquat em rel ação ao gli ifosate. As interações entre os tratamentos de herbicidas e sua reaplicação em 1996 (contrastes 9, 10 e 11), em geral, não foram significativas.

$\mathrm{Na}$ análise de regressão múltipla, encontrou-se a seguinte equação entre biomassa radicular (BR) e atributos do solo: $B R\left(\mathrm{~g} \mathrm{dm}^{-3}\right)=-178,82+76,11$ C orgânico (dag kg-1) - 9,86Al trocável $\left(\mathrm{cmol}_{C} \mathrm{~L}^{-1}\right)+$ $31,85 \mathrm{pH}$ água $\left(\mathrm{R}^{2}=0,727 * * *\right)$, indicando que aumentos na biomassa radicular estão associados a incrementos noteor de $\mathrm{C}$ orgânico eno pH, bem como à redução no teor de Al trocável do solo.

\section{Atributos químicos do solo}

O teor e o estoque de carbono (C) orgânico (Figura 3) indicaram a mesma tendência que a biomassa radicular, verificando-se alta correlação ( $r=0,831^{* * *}$ ) entre $C$ orgânico e bi omassa radicular, considerando todos os dados até à profundidade de $40 \mathrm{~cm}$. Em solo sob vegetação de pradaria, a maior adição (entrada) de C deveu-se à incorporação, senescência, morte e decomposição estacional de raízes (Pieri, 1989; Soriano, 1991).

A regressão não-linear entre C orgânico e profundidade do solo de 2,5 a $25 \mathrm{~cm}$ foi : $\mathrm{C}$ (dag kg-1) $=7,25$ profundidade $-1,736(\mathrm{~cm})\left(\mathrm{R}^{2}=0,904 * * *\right)$, mostrando uma intensa diminuição no teor de $\mathrm{C}$ com o aumento na profundidade do solo.

As diferenças no teor de C orgânico entre os tratamentos foram mais acentuadas esignificativas 
nos primeiros $5 \mathrm{~cm}$ de profundidade. Os valores extremos superiores foram de $1,41 \mathrm{dag} \mathrm{kg}^{-1} \mathrm{de} C$ para a testemunha e de $1,23 \mathrm{dag} \mathrm{kg}^{-1}$ deC para otratamento controlado com paraquat. Ainda que a diferença entre os val ores absolutos extremos não tenha sido maior que 0,18 dag $\mathrm{kg}^{-1}$, a diferença significativa foi entre a testemunha e os tratamentos que tiveram a aplicação de herbicida (contraste 1). Essa diferença foi atribuída ao efeito provocado pel os herbicidas sobre a vegetação, o qual repercutiu na bi omassa radicular, afetando, por conseqüência, o teor de $\mathrm{C}$ orgânico, mostrando a importância do sistema radicular na manutenção e, ou, no aumento do teor de C do solo. SegundoBoadbent \& Nakashima (1974) eBalesdent \& Balabane (1996), a taxa de decomposição do $C$ radicular foi menor quea do $C$ da parte aérea das plantas, decorrente da maior relação lignina/ nitrogênio das raízes e, ou, da incorporação de

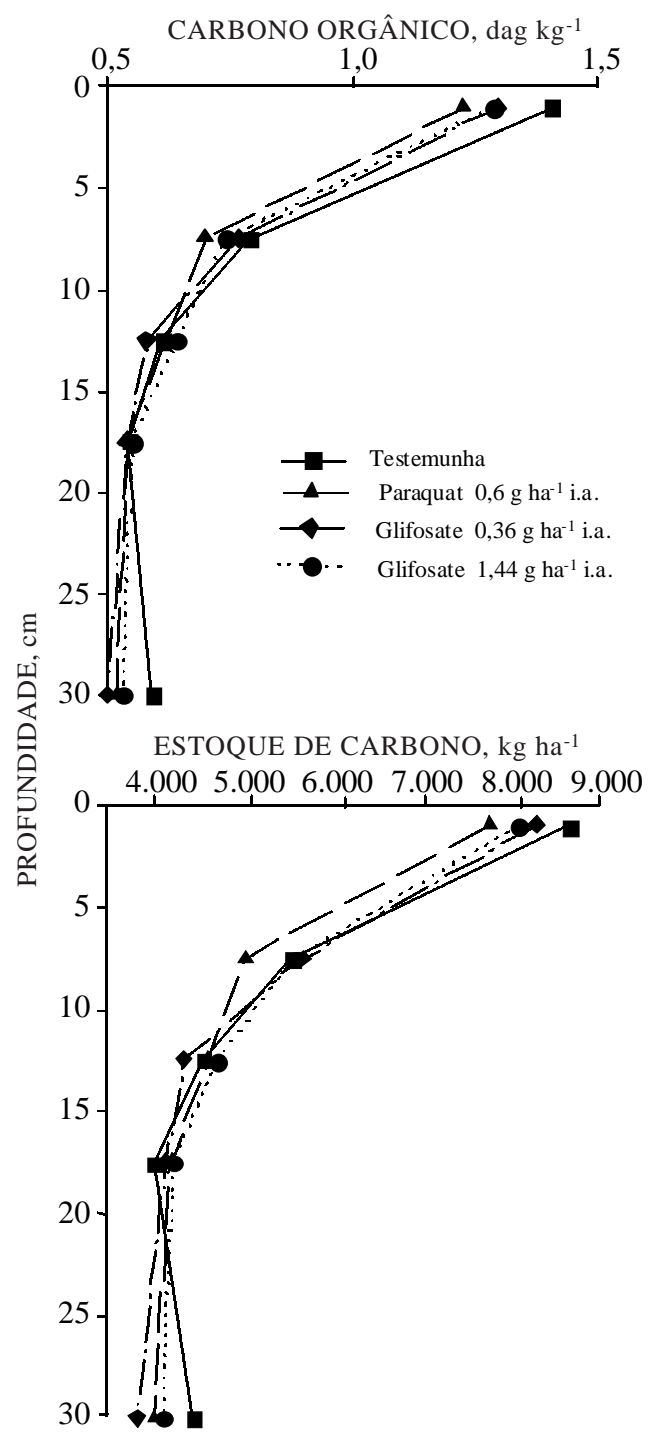

Figura 3. Variação do carbono orgânico e estoque de carbono com a profundidade para diferentes tratamentos com herbicidas. produtos radiculares à matriz do solo, protegendoos fisicamente do ataque mi crobiano (Oades, 1995)

Houve efeito da aplicação de her bicidas em 1996 comparado com a não-aplicação no mesmo ano (Figura 4; contraste 5), com diferenças significativas nas profundidades de $15-20$ e $20-30 \mathrm{~cm}$. Na profundidade de $15-20 \mathrm{~cm}$, o mesmo contraste foi significativo também à profundidade $5-10 \mathrm{~cm}$ para biomassa radicular (Figura 2b). Essas variações em profundidade estão associadas às variações da biomassa radicular.

A reaplicação de glifosate (contraste 7$)$ reduziu a biomassa radicular nas profundidades de 5-10, 1015 e 20-30 cm eoC orgânico na profundidade $0-5 \mathrm{~cm}$, enquanto a de paraquat não causou redução; pelo contrário, incrementou os valores de ambas as variáveis. Possivelmente, o uso de paraquat não provocou a morte das espécies nativas existentes nem de suas raízes, e, por outro lado, quando se controlou a vegetação, obteve-se melhor desenvolvimento das espécies semeadas, aportando biomassa radicular diferente da existente no campo natural. O uso do herbicida sistêmico glifosate provocou a morte das plantas, redução na biomassa radicular nativa e correspondente diminuição no teor de C orgânico. Com essa situação houve melhor desenvol vimento das espécies introduzi das, mas não o suficiente para compensar o efeito da redução da biomassa radicular no teor de C orgânico do solo.

O efeito do uso de herbicida sobre a biomassa radicular também foi significativo nos primeiros $5 \mathrm{~cm}$ de solo. Consi derando esseestrato do sol o como o mais rico em raízes, as modificações nelas provocadas foram detectadas pelas diferenças nos teores de $\mathrm{C}$ orgânico.

A redução do teor de $\mathrm{C}$ orgânico, decorrente do uso de herbicidas na semeadura direta continuada sobre campo natural, foi menor que a redução provocada pelo preparo de sol o com movimentação em semeadura convencional. Neste trabal ho, pôdese observar uma diminuição, no caso extremo, de $13 \%$ na camada de 0-5 cm; no entanto, no caso de preparo convencional em sol o arenoso, essa variação em dois anos chegou a significar uma redução de $50 \%$ na camada de 0-20 cm (Pérez Gomar \& Bemhaja, 1992).

Houve diferença significativa de estoque de $C$ na profundidade de $0-5 \mathrm{~cm}$ (contraste 1 ). O estoque de C para a testemunha foi de $8.650 \mathrm{~kg} \mathrm{ha}^{-1}$ e para os tratamentos que tiveram aplicação de herbicida foi de $8.065 \mathrm{~kg} \mathrm{ha}^{-1}$.

A variação da soma de bases e das bases trocáveis (Figuras 5 e 6) acompanhou a distribuição do C orgânico em profundidade, exceto o Na. Nos tratamentos de controle da vegetação, não apareceram diferenças significativas na soma de bases, talvez por serem pequenas as modificações nos teores de matéria orgânica capazes de provocar variações significativas em CTC e nas bases. 


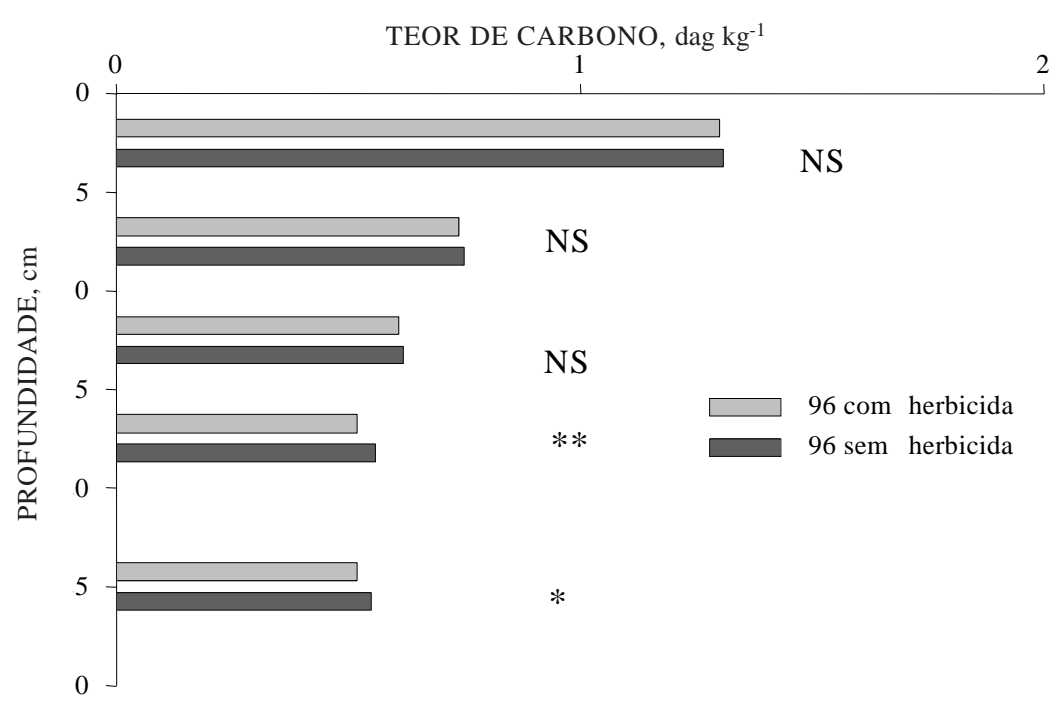

Figura 4. Variação no teor de carbono orgânico com a profundidade com reaplicação ou não de herbicidas em 1996. ( $N S$ = não-significativo; $*=$ significativo $(P<0,05)$; $* *=$ significativo $(P<0,01)$.
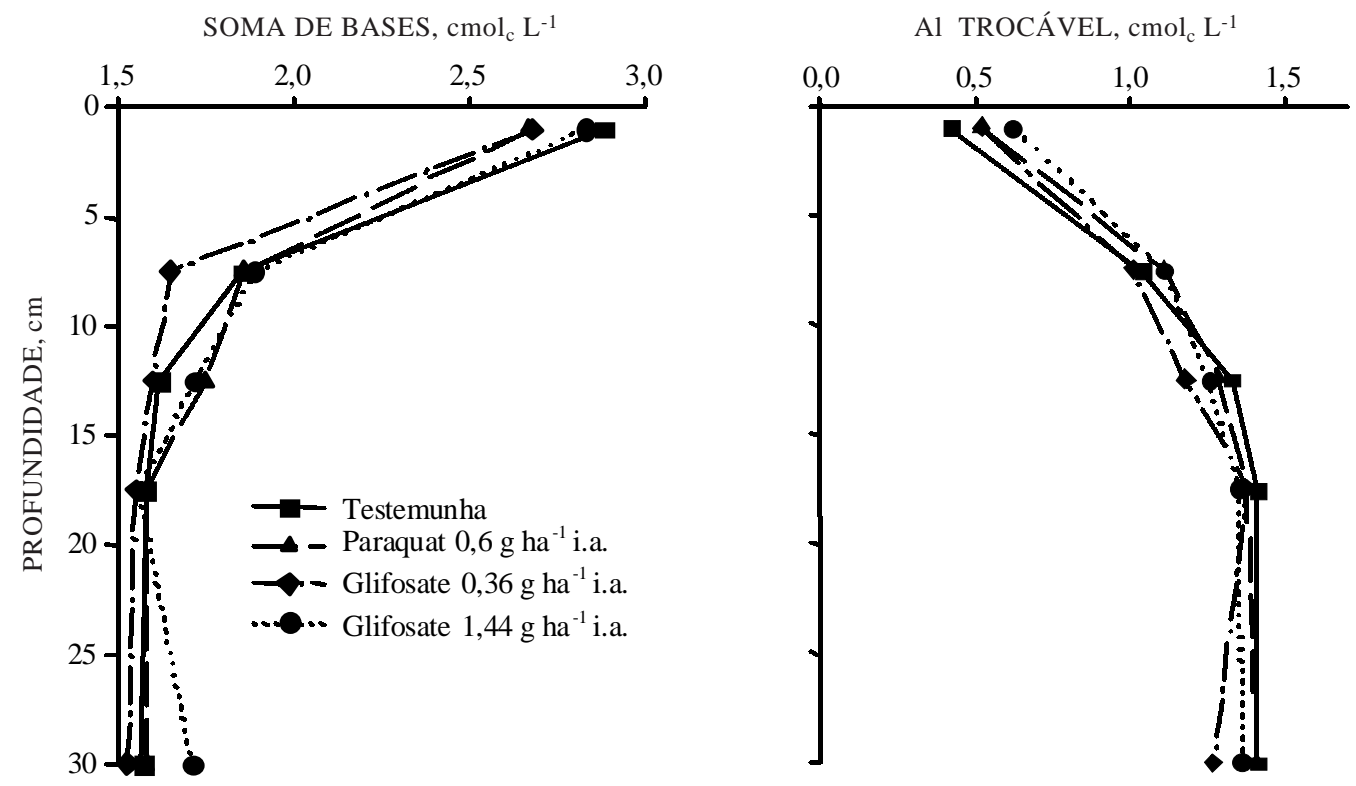

Figura 5. Variação da soma de bases e Al trocável com a profundidade do solo para diferentes tratamentos com herbicidas.

Houve aumento no teor de Al trocável com a profundidade do solo (Figura 5), coincidindo com uma diminuiçãona soma de bases e uma diminuição na matéria orgânica, concordando com os resultados do levantamento de solos do U ruguai realizado por Duran (1985). Nos primeiros centímetros de solo, é provável que a matéria orgânica esteja complexando o Al (Salet, 1994), reduzindo o seu teor trocável.

O teor de C orgânico foi maior nas parcelas onde não se aplicou herbicida, coincidindo com os val ores mais baixos de acidez trocável. O tratamento com mai or control e de vegetação apresentou o menor teor de C orgânico e os valores mais altos deAl trocável.

$\mathrm{O}$ pH (Figura 7) foi inversamente relacionado com o Al trocável. Os teores de Al trocável e de $\mathrm{pH}$ foram os parâmetros mais sensíveis às pequenas variações nos teores de $\mathrm{C}$ orgânico. Houve correlação entre C orgânico eAl trocável na camada de $0-5 \mathrm{~cm}$ $\left(r=-0,279^{*}\right)$.

A regressão linear múltipla entre $A$ l trocável e outros atributos desol o eraiz foi : Al trocável $\left(\mathrm{amol}_{\mathrm{C}} \mathrm{L}^{-1}\right)$ $=8,432-0,496 \mathrm{C}$ orgânico (dag kg-1) $-1,759 \mathrm{pH} \mathrm{KCl}$ $-0,004$ biomassa radicular $\left(\mathrm{g} \mathrm{dm}^{-3}\right)\left(\mathrm{R}^{2}=0,446^{* * *}\right)$. 
Na TROCÁVEL, $\mathrm{cmol}_{\mathrm{c}} \mathrm{L}^{-1}$

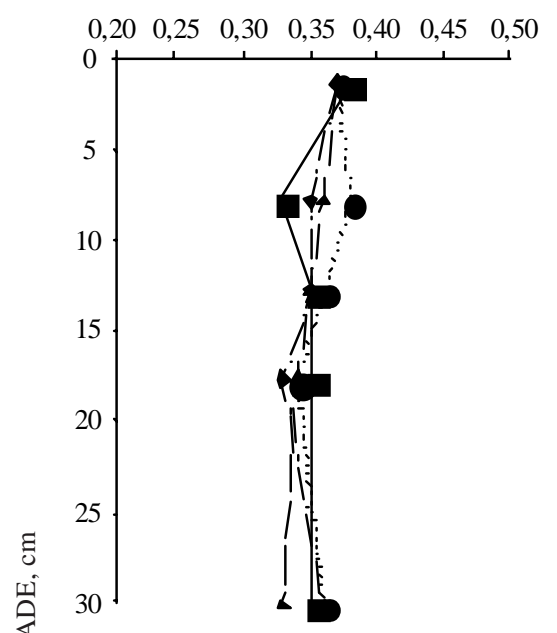

Ca TROCÁVEL, $\mathrm{cmol}_{\mathrm{c}} \mathrm{L}^{-1}$

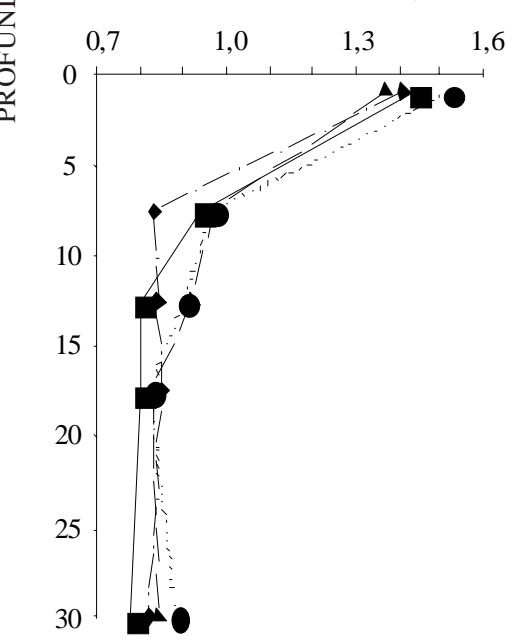

K TROCÁVEL, $\mathrm{cmol}_{\mathrm{c}} \mathrm{L}^{-1}$

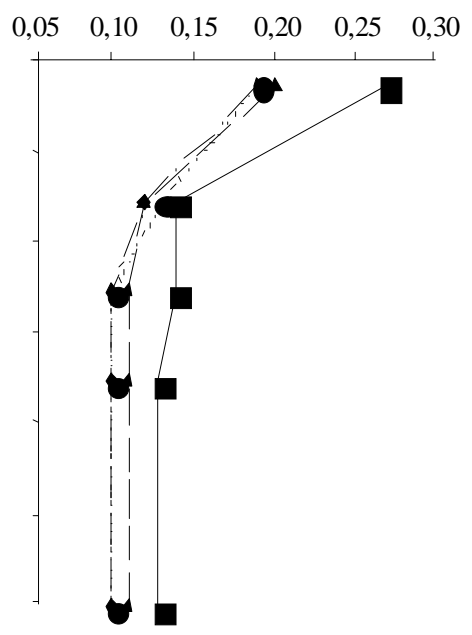

Mg TROCÁVEL, $\mathrm{cmol}_{\mathrm{c}} \mathrm{L}^{-1}$
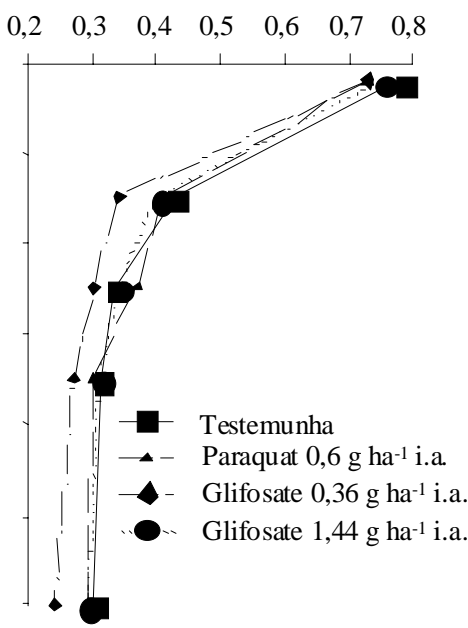

Figura 6. Variação dos teores de $\mathrm{Na}, \mathrm{K}, \mathrm{Ca}$ e Mg trocáveis com a profundidade do solo para diferentes tratamentos com herbicidas.
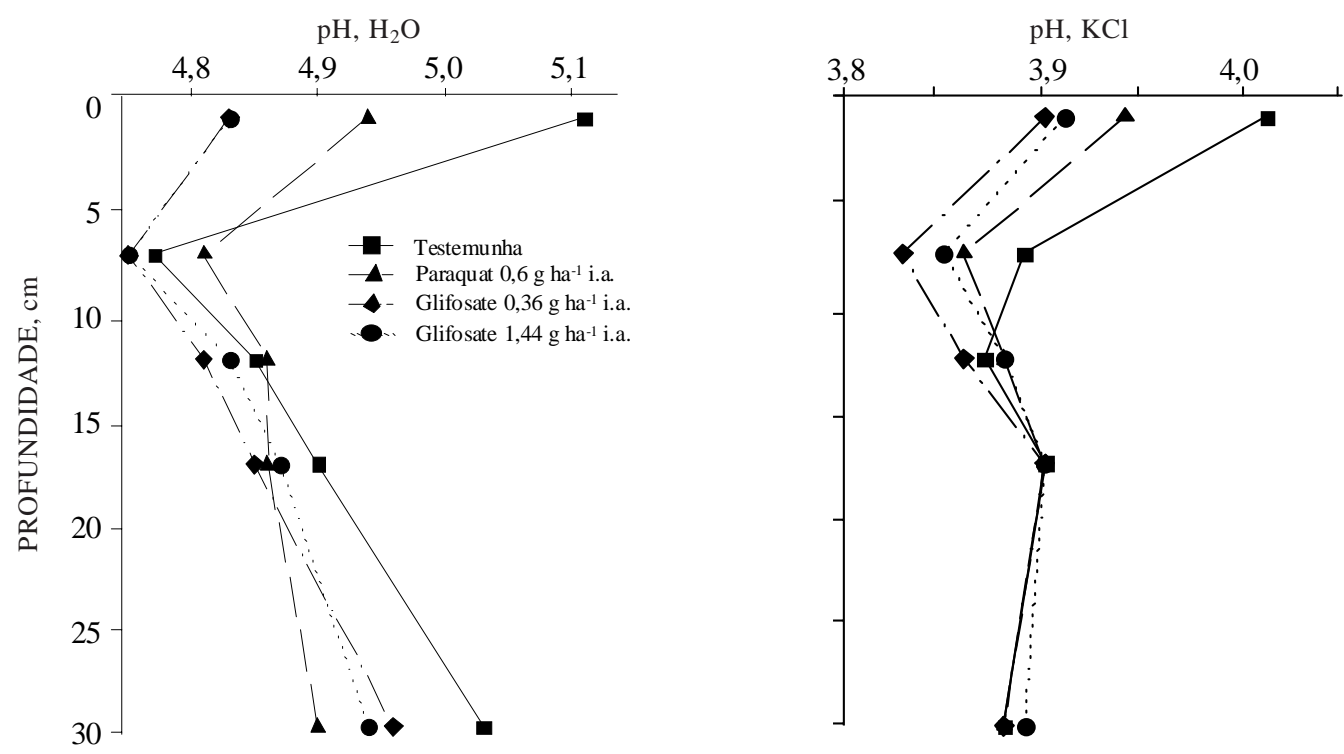

Figura 7. Variação do $\mathrm{pH}$ em $\mathrm{H}_{2} \mathrm{O}$ e em $\mathrm{KCl}$ com a profundidade do solo para diferentes tratamentos com herbicidas. 
O teor deAl trocável foi significativamentemenor na testemunha $\left(0,42 \mathrm{cmol}_{C} L^{-1}\right)$, em relação à média dos tratamentos que receberam herbicidas $\left(0,55 \mathrm{cmol}_{\mathrm{C}} \mathrm{L}^{-1}\right)$ (contraste 1, Figura 8). Na camada superficial, o teor de Al trocável foi maior (contraste 3) no tratamento com 1,44 g ha-1 i.a. de gl ifosate $\left(0,62 \mathrm{cmol}_{\mathrm{c}} \mathrm{L}^{-1}\right)$ do que com $0,36 \mathrm{~g} \mathrm{ha}^{-1}$ i.a. de glifosate $\left(0,52 \mathrm{cmol}_{c} \mathrm{~L}^{-1}\right)$. A interação da reaplicação ou não de herbicidas em 1996 foi significativa (contrastes 10 e 11). O primeiro contraste indica que a tendência no efeito da reaplicação sobre oAl trocável foi diferente entre os tratamentos com glifosate e o tratamento com paraquat. A reaplicação de glifosate aumentou oAl e a de paraquat reduziu o Al (Figura 8). Esse comportamento concorda com os resultados de biomassa radicular e de $\mathrm{C}$ orgânico, anteriormente discutidos.

$\mathrm{O} \mathrm{pH}$ em água e em $\mathrm{KCl}$ (Figura 7) também apresentou diferenças significativas na profundidade de $0-5 \mathrm{~cm}$ (contraste 1 ). $\mathrm{O}$ pH emágua, quando não se aplicou herbicida, foi de 5,1 e, quando se aplicou, foi de 4,9. $\mathrm{O} \mathrm{pH}$ em $\mathrm{KCl}$, quando não se aplicou herbicida, foi de 4,0 e, quando se aplicou, foi de 3,9.

Houve correlação entre $C$ orgânico eAl trocável ( $r=-0,590 * * *)$. Os maiores valores de $C$ orgânico foram observados na testemunha, coincidindo com os menores valores de Al trocável. Salet (1994) concluiu que o efeito complexante da matéria orgânica sobreoAl determinou menores teores desse el emento na soluç̧ão do solo, embora a concentração de Al em solução possa aumentar com a liberação doAl fortemente complexado com a matéria orgânica (Mendonça \& Rowell, 1994). Outro aspecto a assinalar é que pequenas variações nos teores de C orgânico repercutiram nos valores de Al trocável (Mendonça, 1995).

\section{Atributos físicos do solo}

Os valores de densidade do solo na camada de 0-5 cm foram inferiores aos das demais camadas, relacionando-se inversamenteao teor de C orgânico. A testemunha mostrou, nas diferentes profundidades estudadas, menor densidade do sol o que a média dos tratamentos que receberam aplicação de herbicida. O contraste 1 foi significativo nas profundidades de 5-10 cm e de 15-20 cm (Figura 9).

E m sol os arenosos como este ( $100 \mathrm{~g} \mathrm{~kg}^{-1}$ de argila e $800 \mathrm{~g} \mathrm{~kg}^{-1}$ de areia, fundamental mente areia fina e muito fina), a matéria orgânica e as raízes foram determinantes da agregação (Reinert, 1993; Reinert et al., 1998) e do espaço poroso e, por conseguinte, da densidade do solo. A decomposição da biomassa radicular permitiu melhor arranjo das partículas de areia fina, resultando em maior densidade do solo. Reinert et al. (1998) afirmaram que, em solos com textura superficial arenosa, a matéria orgânica foi de grande importância para a formação de agregados e determinação de maior espaço poroso, resultando em menor densidade de solo.

A equação de regressão múltipla encontrada entre a densidade do solo $\left(\rho_{\mathrm{s}}\right)$ e atributos de solo e raiz foi: $\rho_{\mathrm{s}}\left(\mathrm{Mg} \mathrm{m}^{-3}\right)=1660-0,262 \mathrm{C}$ orgânico $\left(\right.$ dag kg $\left.{ }^{-1}\right)$ - 0,0006 biomassa radicular $\left(\mathrm{g} \mathrm{dm}^{-3}\right)\left(\mathrm{R}^{2}=0,727^{* * *}\right)$.

A distribuição de agregados por tamanho e os valores de diâmetro médio ponderado (DMP) e geométrico (DMG) de agregados estáveis, nas profundidades de $0-5 \mathrm{~cm}$ e de $5-10 \mathrm{~cm}$, para os tratamentos: testemunha, paraquat $0,60 \mathrm{~g} \mathrm{ha}^{-1} \mathrm{i} . \mathrm{a}$. egl ifosate $1,44 \mathrm{~g} \mathrm{ha}^{-1} \mathrm{i}$.a. aplicados todos os anos, são apresentados no quadro 1 . Houve predomínio de agregados de maior tamanho, mas apareceram diferenças significativas nos agregados menores e noDMG na profundidadede $0-5 \mathrm{~cm}$. Notratamento

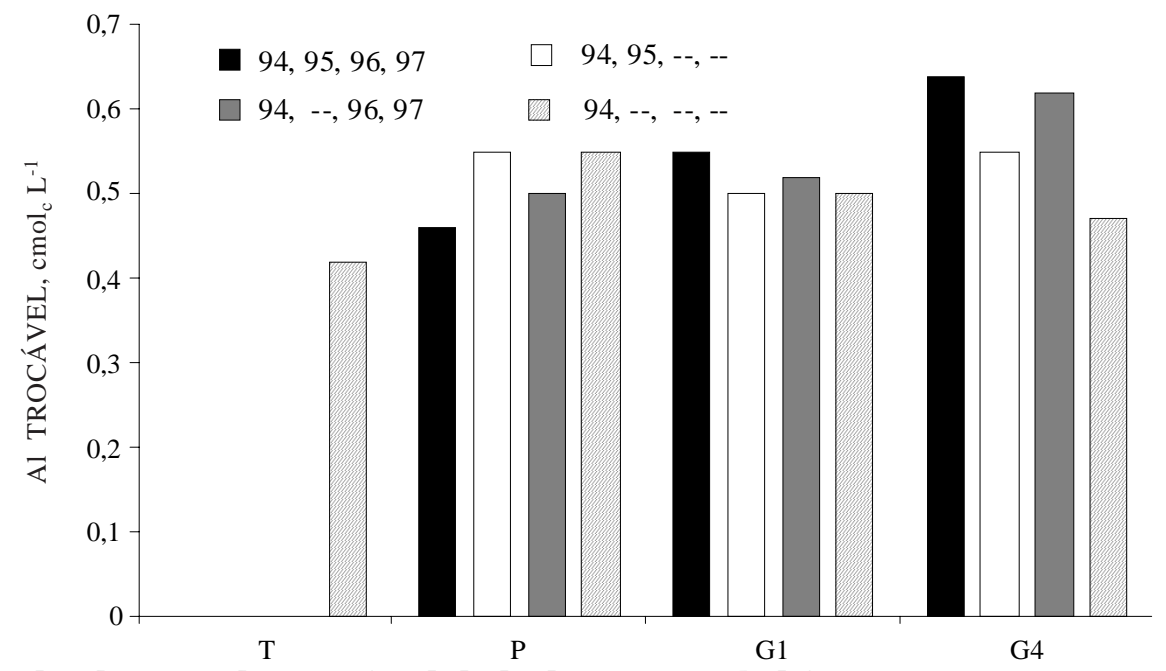

Figura 8. Teores de Al trocável na profundidade de $0-5 \mathrm{~cm}$, sob diferentes tratamentos com herbicidas, aplicados em diferentes anos (- - = sem aplicação, $T=$ testemunha, $P=$ paraquat $0,6 \mathrm{~g} \mathrm{ha}^{-1} \mathbf{i}$. a., $^{-} \mathbf{G 1}=$ glifosate $0,36 \mathrm{~g} \mathrm{ha}^{-1} \mathrm{i}$.a., $\mathbf{G 4}=$ glifosate $1,44 \mathrm{~g} \mathrm{ha}^{-1} \mathrm{i}$.a.). 
com $1,44 \mathrm{~g} \mathrm{a}^{-1} \mathrm{i}$.a. de glifosate, a bi omassa radicular foi reduzida, provocando um incremento de percentagem de agregados menores e um menor DMG.

Silva \& Mielniczuk (1997), estudando o efeito do sistema radicular de plantas sobre a estrutura do solo, encontraram al ta correlação entre a densidade de raízes e a formação e estabilidade de agregados. Os autores assinalaram que as raízes das gramíneas perenes foram responsáveis pela melhor agregação do solo. Para solos arenosos do Rio Grande do Sul, Reinert (1993) mostrou que as modificações em qualidade foram mais intensas e rápidas, obtendose recuperação das propriedades físicas em sistemas que incluíam aportes de matéria orgânica e pouca movimentação do solo. As raízes influíram na integração física das partículas, bem como no aporte deagentes cimentantes pel os exsudatos radiculares epela ativação da biomassa microbiana desenvol vida na rizosfera.

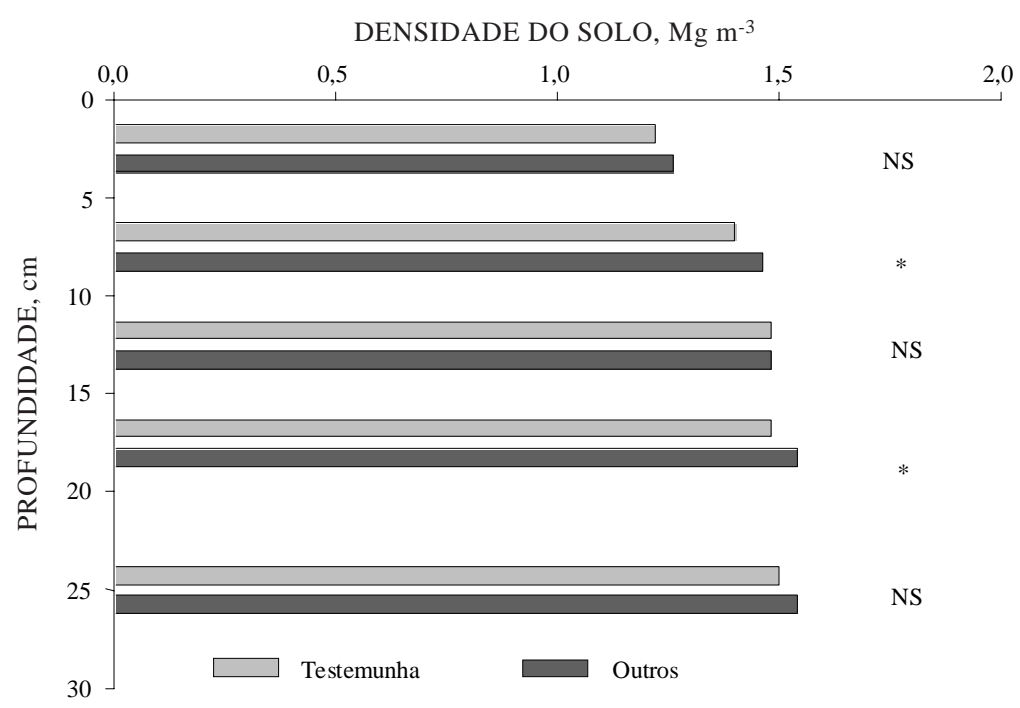

Figura 9. Variação da densidade do solo com a profundidade, considerando a aplicação ou não de herbicidas. (NS = não-significativo; * = significativo $(P<0,05)$; ** = significativo $(P<0,01)$.

Quadro 1. Distribuição por classe de tamanho e diâmetro médio ponderado (DMP) e geométrico (DMG), de agregados estáveis em água, para os tratamentos com herbicidas, e campo nativo não dessecado (testemunha) nas profundidades de 0-5 e 5-10 cm

\begin{tabular}{|c|c|c|c|c|c|c|c|}
\hline \multirow{2}{*}{ Tratamento } & \multicolumn{5}{|c|}{ Agregado estável por classe de tamanho (mm) } & \multirow{2}{*}{ DMP } & \multirow{2}{*}{ DMG } \\
\hline & $8,00-4,76$ & $4,76-2,00$ & $2,00-1,00$ & $1,00-0,21$ & $<0,21$ & & \\
\hline & \multicolumn{5}{|c|}{ - \% } & \multicolumn{2}{|c|}{ 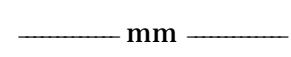 } \\
\hline \multicolumn{8}{|c|}{ Profundidade de $0-5 \mathrm{~cm}$} \\
\hline Testemunha & $70,2 \mathrm{a}$ & $21,7 \mathrm{a}$ & $0,2 \mathrm{a}$ & $0,8 \mathrm{a}$ & $7,1 \mathrm{~b}$ & 5,22 a & $4,07 \mathrm{a}$ \\
\hline $\begin{array}{l}\text { Paraquat } 0,60 \mathrm{~g} \text { i.a. ha-1 } \\
\text { Glifosate } 1,44 \mathrm{~g} \text { i.a. ha-1 }\end{array}$ & $\begin{array}{l}70,0 \text { a } \\
62,3 \text { a }\end{array}$ & $\begin{array}{l}20,1 \text { a } \\
21,4 \text { a }\end{array}$ & $\begin{array}{l}0,3 \mathrm{a} \\
0,3 \mathrm{a}\end{array}$ & $\begin{array}{l}0,7 \mathrm{a} \\
0,7 \mathrm{a}\end{array}$ & $\begin{array}{r}8,9 \mathrm{a} \\
15,3 \mathrm{a}\end{array}$ & $\begin{array}{l}5,19 \mathrm{a} \\
4,70 \mathrm{a}\end{array}$ & $\begin{array}{l}3,86 \mathrm{ab} \\
3,01 \mathrm{~b}\end{array}$ \\
\hline \multicolumn{8}{|c|}{ Profundidade de $5-10 \mathrm{~cm}$} \\
\hline Testemunha & 60,4 a & 24,2 a & 0,6 a & $2,4 \mathrm{a}$ & $12,4 \mathrm{a}$ & 4,7 a & $3,0 \mathrm{a}$ \\
\hline $\begin{array}{l}\text { Paraquat } 0,60 \mathrm{~g} \text { i.a. ha-1 } \\
\text { Glifosate } 1,44 \mathrm{~g} \text { i.a. ha-1 }\end{array}$ & $\begin{array}{l}61,3 \text { a } \\
58,1 \text { a }\end{array}$ & $\begin{array}{l}23,5 \mathrm{a} \\
23,4 \mathrm{a}\end{array}$ & $\begin{array}{l}0,4 \text { a } \\
0,6 \text { a }\end{array}$ & $\begin{array}{l}1,6 \mathrm{a} \\
2,4 \mathrm{a}\end{array}$ & $\begin{array}{l}13,2 \mathrm{a} \\
15,5 \mathrm{a}\end{array}$ & $\begin{array}{l}4,7 \mathrm{a} \\
4,5 \mathrm{a}\end{array}$ & $\begin{array}{l}3,0 \mathrm{a} \\
2,8 \mathrm{a}\end{array}$ \\
\hline
\end{tabular}




\section{CONCLUSÕES}

1. A alteração da composição florística da biomassa aérea ocasionada pela aplicação de herbicidas para a semeadura direta em campo natural em solo arenoso reduziu a biomassa radicular e o carbono orgânico do sol o, especialmente nos primeiros centímetros de profundidade.

2. A redução do carbono orgânico aumentou o teor de Al trocável, enquanto a diminuição da biomassa radicular e do carbono orgânico aumentou a densidade do solo e diminuiu a estabilidade de agregados.

3. Sistemas de produção de pastagens cultivadas que produziram mais biomassa da parte aérea não ocasionaram necessariamente mai or teor de carbono orgânico do sol o, tampouco maior estabilidade de sua estrutura.

\section{LITE RATURA CITADA}

BALESDENT, J . \& BALABANE, M. Major contribution of roots to soil carbon storage inferred from maize cultivated soil. Soil Biol. Biochem., 28:1261-1263, 1996.

BAYER, C. \& MIELNICZUK, J. Características químicas do solo afetadas por métodos de preparo esistemas de cultura. R. Bras. Ci. Solo, 21:105-112, 1997.

BERRETTA, E.J.; MARCHESI, C.G. \& PÉREZ GOMAR, E. Evolución de la vegetación de un campo natural sobre suelo arenoso luego de tres años de siembra directa. In: SEMINÁRIO INTERNACIONAL DO SISTEMA PLANTIO DIRETO, 2., Passo Fundo, 1997. Anais. Passo Fundo, Empresa Brasileira de Pesquisa Agropecuária, 1997. p.285287.

BOHN, H.L.; MCNEAL, L.B. \& O'CONNOR, G. Química del suelo. México, Limusa, 1993. 370p.

BROADBENT, F.E. \& NAKASIMA,T. Mineralization of carbon and nitrogen in soil amended with carbon-13 and nitrogen15 labeled plant material. Soil Sci. Soc. Am. Proc., 38:313315, 1974.

CARÁMBULA, M.;AYALA, W.; CARRIQUIRY,E. \& BERMÚDEZ, R. Siembra de mejoramientos en cobertura. Montevideo, Instituto Nacional de Investigación Agropecuaria, 1994. 20p. (Boletín de Divulgación del INIA, 46)

CARPENEDO, V. \& MIELNICZUK, J. Estado de agregação e qualidade de agregados de Latossolos Roxos, submetido a diferentes sistemas de manejo. R. Bras. Ci. Solo, 14:99105, 1990.

COOK, C.W. \& STUBBENDIECK, J. Studies of root habits and development. In: RANGE research: Basic problems and techniques. Denver, Society for Range Management, 1986. p.82-112.

DORAN, J.W. \& PARKIN,T.B. Defining and assessing soil quality. In: DORAN, J.W.; COLEMAN, D.C.; BEZDOCEK, D.F. \& STEWART, B.A., eds. Defining soil quality for a sustainable environment. Madison, Soil Science Society of America, 1994. p.3-35
DURAN, A. L Los suelos de U ruguay. Montivideo, Hemiferio Sur, 1985. 398p.

KEMPER,W.D. \& CHEPIL,W.S. Size distribution of aggregates. In:BLACK, F.E.; EVANS, D.D.; WHITE, J .L.; ENSMINGER, L.E. \& CLARK, F.E., eds. Methods of soils analysis: Physical and mineralogical properties. Madison, American Society of Agronomy, 1965. p.499-510.

MENDONÇA, E.S. \& ROWELL, D.L. Dinâmica do alumínio e de diferentes frações orgânicas de um Latossolo argiloso sob cerrado e soja. R. Bras. Ci. Solo, 18:295-303, 1994.

MENDONÇA, E.S. Oxidação da matéria orgânica e sua relação com diferentes formas de alumínio de Latossolos. R. Bras. Ci. Solo, 19:25-30, 1995.

MERTEN, G.H. \& MIELNICZUK, J. Distribuição de sistema radicular e dos nutrientes em Latossolo Roxo sob dois sistemas de reparo do solo. R. Bras. Ci. Solo, 15:369-374, 1991.

OADES, J.M. An overview of processes affecting the cycling of carbon in soils. In: ZEPP, R.G. \& SONNTAG, C., eds. The role of non-living organic matter in the earth's carbon cycle. New York, J ohn Wiley, 1995. p.293-303.

PALADINI, F.L.S. \& MIELNICZUK, J. Distribuição detamanho de agregados de um solo Podzól ico Vermel ho-E scuro afetado por sistema de culturas. R. Bras. Ci. Solo, 15:135-140, 1991.

PAZOS, J . I dentificación de los minerales arcillosos de los suel os utilizados en un ensayo de dinámica de potasio. Montevideo, Universidad de la República, 1981. 80p. (Monografia de Graduação)

PÉREZ GOMAR, E. \& BEMHAJA, M. Características y perspectivas de las rotaciones en los suelos arenosos del noreste del Uruguay. R. INIA Invest. Agron., 1:205-213, 1992.

PÉREZ GOMAR, E. \& GARCÍA, F. Manejo de suelos arenosos en Tacuarembó. Montevideo, Instituto Nacional de Investigación Agropecuaria, 1993. 22p. (SérieTécnica, 33)

PIERI, C. Fertilitè des terres de savanes. Montpellier, CIRADIRAT, 1989. 448p.

RASMUSSEN, P.E. \& COLLINS, H.P. Longterm impacts of tillage, fertilizer, and crop residue on soil organic matter in temperate semiarid regions. Adv. Agron., 45:93-134, 1991.

REINERT, D.J. Recuperação da agregação pelo uso de leguminosas e gramíneas em solo Podzólico VermelhoAmarelo. Santa Maria, Universidade Federal de Santa Maria, 1993. 62p. (Tese para Professor Titular)

REINERT, D.J .; AMADO, T.J.C.; REICHERT, J.M. \& FONTINELLI, F. Qualidade de Solos Derivados de Quarzosas da Fronteira Sudoeste do RS: Indicadores Físicos. In: REUNIÃO SUL-BRASILEIRA DE CIÊNCIA DO SOLO, 2., Santa Maria, 1998. Anais. Santa Maria, Núcleo Regional Sul da Sociedade Brasileira de Ciência do Solo, 1998. p.34-38.

SALET, R.L. Dinâmica de íons na sol ução de um sol o submetido ao sistema de plantio direto. Porto Alegre, Universidade Federal do Rio Grande do Sul, 1994. 223p. (Tese de Mestrado) 
SILVA, I.F. \& MIELNICZUK, J. Ação do sistema radicular de plantas na formação e estabilização de agregados do solo. R. Bras. Ci. Solo, 21:113 -117, 1997.

SORIANO,A. Río dela Plata Grasslands. In: Natural grasslands: Introduction and Western hemisphere. Amsterdam, Elsevier, 1991. p.367-407.

SWIFT, M.J. \& WOOMER, M.J. Organic matter and the sustainability of agricultural systems: Definition and measurement. In: MULONGOY, K. \& MERCK, R., eds. Soil organic matter dynamics and sustainability of tropical agriculture. New York, Wiley, 1993. p.3-18.
THOMAS, G.W. Exchangeable cations. In: PAGE, A.L., ed. Methods of soil analysis: Chemical and microbiological properties. 2. ed. Madison, American Society of Agronomy, 1982. p.159-165.

TINSLEY, J. Soil science: Manual of experiments. Aberdeen, University of Aberdeen, 1967. 124p.

WHALLEY, R.D.B. State and transition models for rangelands, successional theory and vegetation change. Trop. Grass., 28:195-205, 1994. 
